\title{
Healthcare use and costs before and after parathyroidectomy in patients on dialysis
}

\author{
Vasily Belozeroff ${ }^{1 *}$, Kerry Cooper ${ }^{1}$, Gregory Hess ${ }^{2}$ and Chun-Lan Chang ${ }^{2}$
}

\begin{abstract}
Background: Parathyroidectomy (PTX) is often performed in dialysis patients when medical treatment fails to control secondary hyperparathyroidism (SHPT). PTX is viewed by many as a cost-containing measure for patients who have been treated with vitamin $D$ analogs and calcimimetics. Yet, information about health resource utilization and costs before and after PTX is limited.

Methods: This retrospective cohort study used professional service and pharmacy claims to identify subjects on dialysis undergoing PTX from 1/1/2008-12/31/2010. Only subjects with at least six months of information before and after PTX were considered. Subjects with primary hyperparathyroidism or kidney transplant were excluded. Prescription use, physician encounters, and surgical complications were compared during the six months immediately before and after PTX.
\end{abstract}

Results: The mean (SD) age of the 181 study subjects was 51 (15) years; 59\% female; and 80\% insured by Medicare. Overall, the percentage of patients receiving medications to manage altered mineral metabolism increased from $67 \%$ before to $79 \%$ after PTX. Specifically, oral vitamin D use increased, while the utilization of cinacalcet decreased resulting in mean (SD) monthly medication charges decreasing from $\$ 486(507)$ to $\$ 226(288)(p<0.01)$. The mean (SD) number of physician encounters rose from 15 (14) before to 21 (22) per 6 months after PTX $(p<0.01)$ resulting in the corresponding increase in mean (SD) monthly charges from \$1531 (2150) to \$1965 (3317) $(p=0.08)$.

Hypocalcemia was the predominant diagnosis recorded for post-surgical physician encounters occurring in $31 \%$ of all subjects; $84 \%$ of hypocalcemic episodes were managed in acute care facilities.

Conclusions: The cost of medications to manage SHPT decreased after PTX largely due to reduction in cinacalcet use, whereas vitamin D use increased likely to manage hypocalcemia. The frequency and cost of physician encounters, especially in acute care settings, were higher in the 6 months after PTX attributable largely to episodes of severe hypocalcemia. Overall, the reduction in prescription costs during the 6 months after PTX is outweighed by the higher costs associated with physician care.

Keywords: Secondary hyperparathyroidism (SHPT), Parathyroidectomy, Dialysis, Vitamin D, Hypocalcemia, Healthcare utilization

\section{Background}

Secondary hyperparathyroidism (SHPT) associated with alterations in bone and mineral metabolism is common in patients with chronic kidney disease (CKD) [1-3]. SHPT progresses over time manifesting as increasing parathyroid gland hyperplasia and increasing synthesis of parathyroid hormone (PTH). In patients with CKD on dialysis, SHPT is characterized both by elevations in PTH as well as

\footnotetext{
* Correspondence: vasilyb@amgen.com

'Amgen Inc., One Amgen Center, Dr, Thousand Oaks, CA 91320, USA

Full list of author information is available at the end of the article
}

abnormalities in calcium and phosphorus levels. Previous studies $[4,5]$ have reported that these biochemical abnormalities are associated with adverse health outcomes, including elevated rates of bone fracture, cardiovascular disease, and death [6-8]. It is recommended that patients on dialysis should be monitored for serum calcium and phosphorus every 1-3 months and for PTH every 36 months [1], while the specific target levels of these biomarkers are still being debated [9-15].

Pharmacological intervention for SHPT includes vitamin D analogs, phosphate binders, and calcimimetics

\section{Biomed Central}


$[3,16,17]$. Total or partial surgical removal of parathyroid glands, ie, parathyroidectomy (PTX) is considered when patients fail to respond adequately to medical therapy and is recommended in patients with severe HPT defined by PTH $>800 \mathrm{pg} / \mathrm{mL}$ [17]. Parathyroidectomy is a viable option for such patients according to the current practice guidelines from the Kidney Disease: Improving Global Outcomes (KDIGO) [18]; it generally improves the short-term and long-term profile of biochemical markers [18-21]. However, the major disadvantage of sub-total PTX are the risks involved in operating in the anterior neck if the patient should need a second surgery; while the disadvantage of total PTX with autotransplant lies in the possibility of prolonged hypocalcemia during the waiting period for the auto transplanted parathyroid tissue to become functional [21]. In a recent, comprehensive review of therapeutic strategies, Stack, BC (2012) noted the decline in parathyroidectomy rates in the US in the 1990s and reported an observed favorable response five years post surgery. Yet, the mortality rate is doubled compared to non-operative SHPT patients and the risk of hypoparathyroidism is also increased, particularly for total PTX with auto-transplantation [19]. Long term consequences of PTX have not been studied sufficiently, mainly due to the ethical issues around potential randomization. However, Kestenbaum et al. (2004) in an observational study of Medicare claims found that patients had higher mortality within 90 days post PTX, but better overall survival 12 months after the surgery compared to those receiving medical therapy to control SHPT [22]. Also, improved survival post-PTX has been reported by Iwamoto et al. [23]. Chen et al. (1998) reported low mortality, short length of hospital stay, and high patient satisfaction among elderly patients undergoing PTX [24].

Based on the literature, PTX appears effective in lowering PTH levels albeit not without risks. However, the current literature remains scarce on the impact of parathyroid surgery on healthcare utilization and costs. The objective of our study was to better understand healthcare utilization and charges before and after PTX among CKD patients on dialysis.

\section{Methods}

This retrospective cohort study was based on the data from private practice provider medical claims (Centers for Medicare and Medicaid Services [CMS]; N $=1500$ records), and National Council for Prescription Drug Programs prescription claims (NCPDP v5.2) in the IMS database. The database contains approximately one billion submitted professional services claims per year, and pharmacy claims for dispensed prescriptions from 50\%$60 \%$ of retail pharmacies across various geographic regions in the United States. All patient-related information is encrypted, de-identified, and compliant with the regulations of the Health Insurance Portability, Affordability and Accountability 1996 (HIPAA 1996).

To be included in the study, patients were required to have at least two professional service claims with ICD-9-CM diagnoses for CKD stage 5 or end stage renal disease (ESRD) at least 30 days apart, and one service claim with the Current Procedural Terminology (CPT) code of 60500, 60502 or 60505 for PTX procedure(s) during January 2008 and December 2010. The index date was the first procedure date of PTX. Further, patients were excluded from the study if they were younger than 18 years of age as of index date, had primary hyperparathyroidism, or kidney transplant, or fewer than six months of observation before and after PTX.

We analyzed, during the six months before and after PTX, the pharmacy claims for drug prescriptions, physician encounters and corresponding charges, and surgical complications recorded in the professional service claims including hematoma or bleeding, vocal cord paralysis or recurrent laryngeal nerve injury, hypocalcemia, wound infection and seroma formation. Descriptive statistics, i.e. means, standard deviation (SD) and median, were reported for continuous variables; the number and percentage of patients were reported for categorical variables. The paired $\mathrm{t}$-tests and McNemar tests were performed to assess the differences before and after PTX. All the statistical analyses were executed with Stata 12.1 (StataCorp LP. College Station, TX).

\section{Results}

The present study identified 181 patients on dialysis undergoing PTX between 2008 and 2010. Their mean (SD) age was 51.1 (14.7) years. Female patients accounted for $59.1 \%$ of the study cohort. Almost half of the study cohort inhabited the South census region and $80.1 \%$ were insured by Medicare (Table 1).

Overall the study patients incurred the mean (SD) charges of $\$ 4529$ (2902) for physician care on the index date - the date receiving PTX. (Table 2) The charges for physician care on index date were mostly billed by surgeon (80.7\%) and from inpatient acute care facilities (80.7\%).

Based on prescription filling activities in the pharmacy claims, more patients received pharmacotherapy to manage SHPT-related biochemical abnormalities after PTX than before $(66.9 \%$ pre vs $75.8 \%$ post; $p<0.01)$ (Table 3 ). The higher medication use post-surgery was mainly attributed to the increased use of oral vitamin D (calcitriol). The percentage of patients filling scripts for vitamin $\mathrm{D}$ increased from $11.6 \%$ pre- to $59.1 \%$ post-surgery $(p<0.01)$. In contrast, the use of calcimimetics deceased from $34.8 \%$ pre- to $11.6 \%$ post-surgery $(p<0.01)$. The use of phosphate binders remained stable before and after PTX. While the study patients filled more prescriptions on average post-surgery compared to pre-surgery, their monthly 
Table 1 Patient demography

\begin{tabular}{lcc}
\hline & $\mathbf{N}$ & $\%$ \\
\hline Number of patients & 181 & $100 \%$ \\
$\quad$ Mean (SD) & 51.1 & \\
$\quad$ Median & 52 & \\
Age group & & \\
18-44 & 61 & $33.7 \%$ \\
$45-64$ & 82 & $45.3 \%$ \\
65-74 & 31 & $17.1 \%$ \\
$75+$ & 7 & $3.9 \%$ \\
Female & 107 & $59.1 \%$ \\
Census region & & \\
Northeast & 14 & $7.7 \%$ \\
Midwest & 38 & $21.0 \%$ \\
South & 90 & $49.7 \%$ \\
West & 39 & $21.5 \%$ \\
Payer type & & \\
Commercial & 28 & $15.5 \%$ \\
Medicare & 145 & $80.1 \%$ \\
Medicaid & 8 & $4.4 \%$ \\
\hline
\end{tabular}

charges in prescriptions filled to manage SHPT decreased from $\$ 486(\mathrm{SD}=507)$ pre- to $\$ 226(\mathrm{SD}=288)$ postsurgery $(p<0.01)$.

Patients had more all-cause physician encounters after PTX than before PTX (Table 4). The mean number (SD) of all-cause physician encounters during a six-month period increased from 15.1 (14.1) pre-surgery to 20.7 (22.0) post-surgery $(p<0.01)$. A higher percentage of patients received acute inpatient care attended by their physician care team post-surgery than pre-surgery (79.0\% post vs $43.1 \%$ pre; $p<0.01$ ); the mean (SD) of six-month physician encounters in the acute inpatient setting increased from 4.5 (9.3) pre-surgery to 10.5 (16.1) post-surgery $(p<0.01)$. However, physician encounters in the acute inpatient setting accounted for a significant increase, whereas fewer patients had encounters in physician offices or outpatient clinics after the surgery $(70.2 \%$ post vs. $89.0 \%$ pre; $p<0.01)$. The average physician encounters in the offices or outpatient clinics is fewer during the six-month period of post-surgery than prior to the surgery $(3.5, \mathrm{SD}=4.6$ post vs $4.3, \mathrm{SD}=5.1$; pre: $p=0.03)$. Healthcare charges billed by physicians also had a marked increase after PTX (Table 5). The mean(SD) monthly charges for all-cause encounters (excluding the actual surgery costs) rose from \$1531 (2150) pre-surgery to $\$ 1965$ (3317) post surgery $(p=0.08)$. The mean (SD) charges in the acute inpatient setting increased significantly from $\$ 681$ (1474) pre-surgery to $\$ 1209$ (1706) postsurgery on average $(p<0.01)$. Furthermore, approximately one-third of patients had evidence of possible surgeryrelated complications identified in the professional service claims. Hypocalcaemia was the most frequently diagnosed condition related to surgery and accounted for $90 \%$ of patients with possible surgery-related complications (Table 6).

\section{Discussions}

This study presented the estimates of short-term healthcare utilization and expenses before and after PTX among patients on dialysis in the U.S. The results from our study suggest that after PTX, the overall cost of medications to manage SHPT decreases largely because of the reduction in the use of cinacalcet. However, vitamin $\mathrm{D}$ use increases post-surgery, although the net effect on cost is downward because of a shift to greater use of calcitriol as

Table 2 Charges of physician care on the index date for PTX

\begin{tabular}{|c|c|c|c|c|c|}
\hline & \multicolumn{2}{|c|}{ Number (\%) of patients } & \multicolumn{3}{|c|}{ Charges of physician care on index date } \\
\hline & $\mathbf{N}$ & $\%$ & Mean & SD & Median \\
\hline All patients & 181 & $100.0 \%$ & 4,529 & 2,902 & 3,707 \\
\hline \multicolumn{6}{|c|}{ Charges of physician care on index date, by physician Specialty } \\
\hline Surgeon & 146 & $80.7 \%$ & 3,742 & 2,060 & 3,212 \\
\hline Nephrologists & 57 & $31.5 \%$ & 230 & 201 & 158 \\
\hline Primary care & 10 & $5.5 \%$ & 711 & 1,595 & 211 \\
\hline Other specialties & 93 & $51.4 \%$ & 2,723 & 2,464 & 1,901 \\
\hline \multicolumn{6}{|c|}{ Charges of physician care on index date, by service place } \\
\hline Emergent departments/urgent care centers & 0 & $0.0 \%$ & NA & NA & NA \\
\hline Inpatient acute care facilities & 146 & $80.7 \%$ & 3,702 & 2,871 & 3,137 \\
\hline Office/outpatient clinics & 3 & $1.7 \%$ & 870 & 849 & 675 \\
\hline Outpatient hospitals & 62 & $34.3 \%$ & 3,758 & 3,006 & 2,957 \\
\hline Other/unknown service places & 15 & $8.3 \%$ & 2,914 & 2,349 & 2,110 \\
\hline
\end{tabular}


Table 3 Prescription use and charges before and after Parathyroidectomy

\begin{tabular}{|c|c|c|c|c|c|}
\hline \multirow{2}{*}{ Patients with medication use for: $(\mathrm{N}, \%)$} & \multicolumn{2}{|c|}{ Before $(\mathrm{N}=181)$} & \multicolumn{2}{|c|}{ After $(\mathrm{N}=181)$} & P value \\
\hline & & & & & \\
\hline Any prescriptions for SHPT management & 121 & $66.9 \%$ & 142 & $78.5 \%$ & $<0.01$ \\
\hline Calcimimetics & 63 & $34.8 \%$ & 21 & $11.6 \%$ & $<0.01$ \\
\hline Bisphosphonates & 0 & $0.0 \%$ & 0 & $0.0 \%$ & NA \\
\hline Phosphate binders & 98 & $54.1 \%$ & 95 & $52.5 \%$ & 0.7 \\
\hline Teriparatide & 0 & $0.0 \%$ & 0 & $0.0 \%$ & NA \\
\hline Raloxifen & 1 & $0.6 \%$ & 0 & $0.0 \%$ & 1 \\
\hline Vitamin D & 21 & $11.6 \%$ & 107 & $59.1 \%$ & $<0.01$ \\
\hline \multicolumn{6}{|l|}{ Number of filled scripts: (Mean, SD) } \\
\hline All prescriptions & 22.8 & 20.4 & 27.9 & 23.3 & $<0.01$ \\
\hline Prescriptions for SHPT management & 2.6 & 3.3 & 3.2 & 3.2 & 0.05 \\
\hline \multicolumn{6}{|c|}{ Average monthly charges of scripts filled for: (\$; Mean, SD) } \\
\hline All prescriptions & 445 & 459 & 331 & 358 & $<0.01$ \\
\hline Prescriptions for SHPT management & 486 & 507 & 226 & 288 & $<0.01$ \\
\hline
\end{tabular}

compared to more expensive vitamin D analogues, presumably for the management of hypocalcaemia. The frequency and cost of physician encounters, especially in the acute care setting, were higher in the 6-month period post surgery. Hypocalcaemia was the dominant post-surgical complication, and it was associated with additional physician care, often provided in the acute care setting. Overall, the cost reduction in prescriptions during the 6-month post surgical period was outweighed by the cost increase associated with physician care.
From the clinical standpoint, parathyroidectomy is often reserved for the patients who have failed to respond to medical therapy for SHPT. While clinical practice worldwide is variable with respect to indications for and frequency of utilization of PTX, one recent study reports that the PTX rate in the US has fluctuated between 1992 and 2007 from the lowest recorded in 1998 (7.0 per 1000 patient years) to the highest during 2002 (12.8 per 1000 patient years) [25], which could reflect changing treatment patterns and guidelines.

Table 4 Physician care before and after Parathyroidectomy

\begin{tabular}{|c|c|c|c|c|c|}
\hline All-cause encounters in any place & \multicolumn{2}{|c|}{ Before $(\mathrm{N}=181)$} & \multicolumn{2}{|c|}{ After $(\mathrm{N}=181)$} & $P$ value \\
\hline$N(\%)$ of patients $w / \geq 1$ encounter & 181 & $100.0 \%$ & 176 & $97.2 \%$ & 0.06 \\
\hline Mean (SD) of encounters & 15.4 & 14.1 & 20.7 & 22 & $<0.01$ \\
\hline \multicolumn{6}{|c|}{ All-cause encounters in emergency departments/urgent care centers } \\
\hline$N(\%)$ of patients $w / \geq 1$ encounter & 37 & $20.4 \%$ & 56 & $30.9 \%$ & 0.01 \\
\hline Mean (SD) of encounters & 0.5 & 1.4 & 0.8 & 1.8 & 0.05 \\
\hline \multicolumn{6}{|c|}{ All-cause encounters in inpatient acute care facilities } \\
\hline$N(\%)$ of patients $w / \geq 1$ encounter & 78 & $43.1 \%$ & 143 & $79.0 \%$ & $<0.01$ \\
\hline Mean (SD) of encounters & 4.5 & 9.3 & 10.5 & 16.1 & $<0.01$ \\
\hline \multicolumn{6}{|c|}{ All-cause encounters in offices/outpatient clinics } \\
\hline$N(\%)$ of patients $w / \geq 1$ encounter & 161 & $89.0 \%$ & 127 & $70.2 \%$ & $<0.01$ \\
\hline Mean (SD) of encounters & 4.3 & 5.1 & 3.5 & 4.6 & 0.03 \\
\hline \multicolumn{6}{|c|}{ All-cause encounters in outpatient hospitals } \\
\hline$N(\%)$ of patients $w / \geq 1$ encounter & 88 & $48.6 \%$ & 84 & $46.4 \%$ & 0.63 \\
\hline Mean (SD) of encounters & 1.5 & 2.9 & 1.5 & 3.1 & 0.92 \\
\hline \multicolumn{6}{|c|}{ All-cause encounters in other/unknown service places } \\
\hline$N(\%)$ of patients $w / \geq 1$ encounter & 105 & $58.0 \%$ & 107 & $59.1 \%$ & 0.69 \\
\hline Mean (SD) of encounters & 4.7 & 6.5 & 4.5 & 6.7 & 0.7 \\
\hline
\end{tabular}


Table 5 Charges related to physician care

\begin{tabular}{lccccc}
\hline & $\begin{array}{c}\text { Before } \\
(\mathbf{N}=\mathbf{1 8 1})\end{array}$ & $\begin{array}{c}\text { After } \\
(\mathbf{N}=\mathbf{1 8 1})\end{array}$ & $\mathbf{P}$ value \\
\hline $\begin{array}{l}\text { Average monthly charges of } \\
\text { encounters for any cause (\$): }\end{array}$ & & & & & \\
Any service places & & & & & \\
$\quad$ Mean (SD) & 1,531 & 2,150 & 1,965 & 3,317 & 0.08 \\
$\quad$ Median & 880 & & 1,093 & & \\
Emergent departments/urgent & & & & & \\
care centers & & & & & \\
$\quad$ Mean (SD) & 81 & 216 & 155 & 370 & 0.01 \\
$\quad$ Median & 0 & & 0 & & \\
Inpatient acute care facilities & & & & & \\
$\quad$ Mean (SD) & 681 & 1,474 & 1,209 & 1,706 & $<0.01$ \\
$\quad$ Median & 0 & & 618 & & \\
Physician offices/outpatient clinics & & & & & \\
$\quad$ Mean (SD) & 920 & 2,492 & 1,261 & 4,680 & 0.32 \\
$\quad$ Median & 250 & & 152 & & \\
Outpatient hospitals & & & & & \\
$\quad$ Mean (SD) & 587 & 1,539 & 603 & 1,209 & 0.89 \\
Median & 0 & & 0 & & \\
Other/unknown service places & & & & & \\
$\quad$ Mean (SD) & 440 & 827 & 391 & 531 & 0.41 \\
$\quad$ Median & 273 & & 289 & & \\
\hline
\end{tabular}

Parathyroidectomy may also seem appealing from the economic standpoint arguably because of the ability to save downstream costs of pharmacotherapies [26-28]. Our study highlights important short term clinical and economic consequences of PTX which have not been described previously. Although PTX is effective in lowering serum PTH [29-34], it also commonly results in persistent, inappropriately low PTH levels with the inherent risk of hypocalcemia and adynamic bone disease [35-39].

Table 6 Possible complications after surgery

\begin{tabular}{lcc}
\hline & N & $\%$ \\
\hline Number of patients & 181 & $100 \%$ \\
Patients with any possible surgical complications & 61 & $33.7 \%$ \\
$\quad$ Hematoma/bleeding & 5 & $2.8 \%$ \\
$\quad$ Vocal cord paralysis/recurrent laryngeal nerve injury & 1 & $0.6 \%$ \\
$\quad$ Severe hypocalcaemia & 56 & $30.9 \%$ \\
$\quad$ Wound infection & 1 & $0.6 \%$ \\
$\quad$ Seroma formation & 1 & $0.6 \%$ \\
Mean (SD) of 6-month physician encounters for & 5.5 & 6.4 \\
possible complications & & \\
$\begin{array}{l}\text { Mean (SD) of 6-month total charges of } \\
\text { physician encounters for possible complications (\$) }\end{array}$ & 1,009 & 959 \\
$\begin{array}{l}\text { Mean (SD) of monthly charges of physician } \\
\text { encounters for possible complications (\$) }\end{array}$ & 726 & 654 \\
\hline
\end{tabular}

Additionally, about $10-30 \%$ of CKD patients undergoing either subtotal or total PTX still experienced persistent or recurrent SHPT after the surgery [22-24,26,27,29].

\section{Limitations of study}

This study has several limitations. Parathyroidectomy is not a very common surgery within the general or CKD population. The study design required at least six months of information before and after PTX; the post PTX cost may have been underestimated. The short study duration was selected because there is no comparator group outside of PTX and the design assumes the intervention of interest. In addition, the study utilized the CPT codes of 60500,60502 and 60505 to identify patients undergoing PTX. These CPT codes cannot differentiate surgical procedures between total PTX with autotransplantation, and subtotal PTX.

Race, or ethnicity, is generally not available in the professional, medical service claims or pharmacy claims. Thus, it is difficult to evaluate the differences of received treatment and care utilization among different racial or ethnic groups in this study.

This study did not find any claims activities related to the use of IV vitamin D in private practitioner claims or calcium supplement in the pharmacy claims. This is because such patients often receive injectable medications at the dialysis centers making it likely to be recorded in the medical charts in the centers or institutional claims (CMS1450 form) rather than in professional medical service claims (CMS-1500 form) which was used in this study. Calcium supplements are often available over-the-counter and not included in the prescription formularies.

This study also attempted to bridge the information in the medical and pharmacy claims with laboratory results from a national laboratory provider in order to better understand the changes of clinical endpoints such as serum calcium, phosphorus, PTH and vitamin D before and after PTX. However, there were only few patients who had information available in both claims and laboratory data. It is conceivable that most dialysis patients' routine blood work is captured within the dialysis centers rather than in facilities outside dialysis centers. Furthermore, the laboratory results are under-reported in the professional service claims (CMS-1500 form) due to the fact most of the laboratory results are not required for reimbursement of professional services.

The professional service and pharmacy claims largely reflect the charges and payments for delivered health services. Neither are designed for research needs to provide patient medical history to assess the disease severity and progression, nor to evaluate cost as these claims tend to be non-adjudicated claims. Finally, the continuum of care may not be fully observed in the claimsbased study since treatment may be provided at a 
healthcare site not reported in the claims or at another practice site.

\section{Conclusion}

Our study showed that cost of medications to manage SHPT decreased after PTX largely due to reduction in cinacalcet use, whereas vitamin D (calcitriol) use increased likely to manage hypocalcemia. The frequency and cost of physician encounters, especially in acute care settings, were higher in the 6 months after PTX attributable largely to episodes of severe hypocalcemia. Overall, the reduction in prescription costs during the 6 months after PTX is outweighed by higher costs associated with physician care. The impact of PTX on postoperative healthcare utilization and charges may be a consideration in the treatment decisions for dialysis patients for whom all medical options have been exhausted.

\section{Abbreviations}

CKD: Chronic kidney disease; CMS: Center for Medicare and Medicaid Services; CPT: Current procedural terminology; ESRD: End-stage renal disease; ICD-9: International classification of diseases, ninth edition, clinical modification; IV: Intravenous; PTH: Parathyroid Hormone;

PTX: Parathyroidectomy; SHPT: Secondary hyperparathyroidism; SD: Standard deviation.

\section{Competing interests}

The study was funded by Amgen Inc. VB and KC are employees and shareholders of Amgen. GH and CLC are employees of IMS Health.

\section{Authors' contributions}

VB and KC conceived the study. All authors contributed to study design. CLC directed the data extraction and management and performed the statistical analyses in consultation with VB, KC and GH. CLC drafted the manuscript and all authors contributed to critically revising the paper. Finally, all authors read and approved the submitted manuscript.

\section{Acknowledgements}

We would like to thank Innokentiy Kasatkin for his assistance in data extraction and management and Ajita De for her assistance in manuscript preparation as well as Holly Tomlin (employee and stockholder, Amgen Inc) for her editing and journal formatting assistance.

\section{Author details}

${ }^{1}$ Amgen Inc., One Amgen Center, Dr, Thousand Oaks, CA 91320, USA. ${ }^{2}$ IMS Health, One IMS Drive, Plymouth Meeting, PA, USA.

\section{Received: 21 December 2012 Accepted: 18 June 2013}

Published: 2 July 2013

\section{References}

1. Moe SM, Drüeke TB, Block GA, et al: KDIGO clinical practice guideline for the diagnosis, evaluation, prevention, and treatment of Chronic Kidney DiseaseMineral and Bone Disorder (CKD-MBD). Kidney Int Suppl 2009, 76:S1-S130.

2. Tomasello S: Secondary Hyperparathyroidism and Chronic Kidney Disease. Diabetes Spectrum 2008, 21:19-25.

3. De Francisco ALM: Secondary Hyperparathyroidism: Review of the Disease and Its Treatment. Clinical Therapeutics 2004, 26:12.

4. Levin A, Bakris GL, Molitch M, Smulders M, Tian J, Williams LA, Andress DL: Prevalence of abnormal serum vitamin D, PTH, calcium, and phosphorus in patients with chronic kidney disease: results of the study to evaluate early kidney disease. Kidney Int 2007, 71:31-38.

5. Vassalotti JA, Uribarri J, Chen S-C, Li S, Wang C, Collins AJ, Calvo MS, Whaley-Connell AT, McCullough PA, Norris KC: Trends in mineral metabolism: Kidney Early Evaluation Program (KEEP) and the National
Health and Nutrition Examination Survey (NHANES) 1999-2004. Am J Kidney Dis 2008, 51:S56-S68.

6. Block GA, Martin K, De Francisco ALM, Turner SA, Avram MM, Suranyi MG, Hercz G, Cunningham J, Abu-Alfa AK, Messa P, Coyne DW, Locatelli F, Cohen RM, Evenepoel P, Moe SM, Fournier A, Braun J, McCary LC, Zani VJ, Olson KA, Drüeke TB, Goodman WG: Cinacalcet for secondary hyperparathyroidism in patients receiving hemodialysis. N Engl J Med 2004, 350:1516-1525.

7. Danese MD, Kim J, Doan QV, Dylan M, Griffiths R, Chertow GM: PTH and the risks for hip, vertebral, and pelvic fractures among patients on dialysis. Am J Kidney Dis 2006, 47:149-156.

8. Kalantar-Zadeh K, Kuwae N, Regidor DL, Kovesdy CP, Kilpatrick RD, Shinaberger CS, McAllister CJ, Budoff MJ, Salusky IB, Kopple JD: Survival predictability of time-varying indicators of bone disease in maintenance hemodialysis patients. Kidney Int 2006, 70:771-780.

9. Cassidy MJ, Owen JP, Ellis HA, Dewar J, Robinson CJ, Wilkinson R, Ward MK, Kerr DN: Renal osteodystrophy and metastatic calcification in long-term continuous ambulatory peritoneal dialysis. Q J Med 1985, 54:29-48.

10. Fernandez-Reyes MJ, Auxiliadora Bajo M, Robles P, Selgas R, Oliver J, Del Peso G, Garcia G, Jimenez C, Garcia-Gallego F: Mitral annular calcification in CAPD patients with a low degree of hyperparathyroidism. An analysis of other possible risk factors. Nephrol Dial Transplant 1995, 10:2090-2095.

11. Goodman WG, Goldin J, Kuizon BD, Yoon C, Gales B, Sider D, Wang Y, Chung J, Emerick A, Greaser L, Elashoff RM, Salusky IB: Coronary-artery calcification in young adults with end-stage renal disease who are undergoing dialysis. N Engl J Med 2000, 342:1478-1483.

12. Maher ER, Young G, Smyth-Walsh B, Pugh S, Curtis JR: Aortic and mitral valve calcification in patients with end-stage renal disease. Lancet 1987, 2:875-877.

13. Ribeiro S, Ramos A, Brandão A, Rebelo JR, Guerra A, Resina C, Vila-Lobos A, Carvalho F, Remédio F, Ribeiro F: Cardiac valve calcification in haemodialysis patients: role of calcium-phosphate metabolism. Nephrol Dial Transplant 1998, 13:2037-2040.

14. Velentzas C, Meindok H, Oreopoulos DG, Meema HE, Rabinovich S, Jones M, Sutton D, Rapoport A, De Veber GA: Visceral calcification and the CaXP product. Adv Exp Med Biol 1978, 103:195-201.

15. Massry SG, Coburn JW, et al: K/DOQI clinical practice guidelines for bone metabolism and disease in chronic kidney disease. Am. J. Kidney Dis. 2003, 42:S1-S201.

16. Cunningham J, Locatelli F, Rodriguez M: Secondary Hyperparathyroidism: Pathogenesis, Disease Progression, and Therapeutic Options. Clin J Am Soc Nephrol 2011, 6:913-921.

17. Stack BC Jr: Secondary Hyperparathyroidism. British Medical Journal (BMJ) Point of Care 2012. https://online.epocrates.com/u/29111107/Secondary +hyperparathyroidism.

18. Neonakis E, Wheeler MH, Krishnan H, Coles GA, Davies F, Woodhead JS: Results of surgical treatment of renal hyperparathyroidism. Arch Surg 1995, 130:643-648.

19. Gagné ER, Ureña P, Leite-Silva S, Zingraff J, Chevalier A, Sarfati E, Dubost C, Drüeke TB: Short- and long-term efficacy of total parathyroidectomy with immediate autografting compared with subtotal parathyroidectomy in hemodialysis patients. J Am Soc Nephrol 1992, 3:1008-1017.

20. Gasparri G, Camandona M, Abbona GC, Papotti M, Jeantet A, Radice E, Mullineris B, Dei Poli M: Secondary and tertiary hyperparathyroidism: causes of recurrent disease after $\mathbf{4 4 6}$ parathyroidectomies. Ann Surg 2001, 233:65-69.

21. Jofré R, López Gómez JM, Menárguez J, Polo JR, Guinsburg M, Villaverde T, Pérez Flores I, Carretero D, Rodríguez Benitez P, Pérez García R: Parathyroidectomy: whom and when? Kidney Int Supp/ 2003:S97-S100.

22. Kestenbaum B, Andress DL, Schwartz SM, Gillen DL, Seliger SL, Jadav PR, Sherrard DJ, Stehman-Breen C: Survival following parathyroidectomy among United States dialysis patients. Kidney Int 2004, 66:2010-2016.

23. Iwamoto N, Sato N, Nishida M, Hashimoto T, Kobayashi H, Yamasaki S, Ono T, Nishimura M, Tokoro T, Sakoda C, Murakawa M, Okino K, Okamoto Y, Imai R, Adachi N, Ninomiya K, Mabuchi H, Koyama M, Nakanouchi T, Iseki K: Total parathyroidectomy improves survival of hemodialysis patients with secondary hyperparathyroidism. J Nephrol 2012, 25:755-763.

24. Chen $\mathrm{H}$, Parkerson $\mathrm{S}$, Udelsman R: Parathyroidectomy in the elderly: do the benefits outweigh the risks? World J Surg 1998, 22:531-535. discussion 535-536. 
25. Li S, Chen Y, Peng YW, et al: Trends in Parathyroidectomy Rates in US Hemodialysis Patients From 1992 to 2007. Am J Kidney Dis 2011, 57(4):602-611

26. Narayan R, Perkins RM, Berbano EP, Yuan CM, Neff RT, Sawyers ES, Yeo FE, Vidal-Trecan GM, Abbott KC: Parathyroidectomy Versus Cinacalcet Hydrochloride-Based Medical Therapy in the Management of Hyperparathyroidism in ESRD: A Cost Utility Analysis. Am J Kidney Dis 2007, 49:801-813.

27. Schneider R, Kolios G, Koch BM, Fernández ED, Bartsch DK, Schlosser K: An economic comparison of surgical and medical therapy in patients with secondary hyperparathyroidism - the German perspective. Surgery 2010 148:1091-1099.

28. Komaba H, Moriwaki K, Goto S, Yamada S, Taniguchi M, Kakuta T, Kamae I, Fukagawa M: Cost-Effectiveness of Cinacalcet Hydrochloride for Hemodialysis Patients With Severe Secondary Hyperparathyroidism in Japan. Am J Kidney Dis 2012, 60:262-271.

29. Coulston JE, Egan R, Willis E, Morgan JD: Total parathyroidectomy without autotransplantation for renal hyperparathyroidism. Br J Surg 2010, 97:1674-1679.

30. Low T-HH, Clark J, Gao K, Eris J, Shannon K, O'Brien C: Outcome of parathyroidectomy for patients with renal disease and hyperparathyroidism: predictors for recurrent hyperparathyroidism. ANZ J Surg 2009, 79:378-382.

31. Puccini M, Carpi A, Cupisti A, Caprioli R, lacconi P, Barsotti M, Buccianti P, Mechanick J, Nicolini A, Miccoli P: Total parathyroidectomy without autotransplantation for the treatment of secondary hyperparathyroidism associated with chronic kidney disease: clinical and laboratory long-term follow-up. Biomed Pharmacother 2010, 64:359-362.

32. Rayes $N$, Seehofer $D$, Schindler $R$, Reinke $P$, Kahl A, Ulrich F, Neuhaus $P$, Nüssler NC: Long-term results of subtotal vs total parathyroidectomy without autotransplantation in kidney transplant recipients. Arch Surg 2008, 143:756-761. discussion 761.

33. Schneider R, Slater EP, Karakas E, Bartsch DK, Schlosser K: Initial parathyroid surgery in 606 patients with renal hyperparathyroidism. World J Surg 2012, 36:318-326.

34. Stracke S, Keller F, Steinbach G, Henne-Bruns D, Wuerl P: Long-term outcome after total parathyroidectomy for the management of secondary hyperparathyroidism. Nephron Clin Pract 2009, 111:c102-c109.

35. Atsumi K, Kushida K, Yamazaki K, Shimizu S, Ohmura A, Inoue T: Risk factors for vertebral fractures in renal osteodystrophy. Am J Kidney Dis 1999, 33:287-293.

36. Coco M, Rush $\mathrm{H}$ : Increased incidence of hip fractures in dialysis patients with low serum parathyroid hormone. Am J Kidney Dis 2000, 36:1115-1121.

37. Hercz G, Pei Y, Greenwood C, Manuel A, Saiphoo C, Goodman WG, Segre GV Fenton S, Sherrard DJ: Aplastic osteodystrophy without aluminum: the role of "suppressed" parathyroid function. Kidney Int 1993, 44:860-866.

38. Taal MW, Masud T, Green D, Cassidy M: Risk factors for reduced bone density in haemodialysis patients. Nephrol Dial Transplant 1999, 14:1922-1928.

39. Wang M, Hercz G, Sherrard DJ, Maloney NA, Segre GV, Pei Y: Relationship between intact 1-84 parathyroid hormone and bone histomorphometric parameters in dialysis patients without aluminum toxicity. Am J Kidney Dis 1995, 26:836-844.

doi:10.1186/1472-6963-13-248

Cite this article as: Belozeroff et al:: Healthcare use and costs before and after parathyroidectomy in patients on dialysis. BMC Health Services Research 2013 13:248

\section{Submit your next manuscript to BioMed Central and take full advantage of:}

- Convenient online submission

- Thorough peer review

- No space constraints or color figure charges

- Immediate publication on acceptance

- Inclusion in PubMed, CAS, Scopus and Google Scholar

- Research which is freely available for redistribution 